\title{
Rebating Antitrust Fines to Encourage Private Damages Actions*
}

\author{
Winand Emons ${ }^{\dagger} \quad$ Severin Lenhard ${ }^{\ddagger}$
}

Version: July 2020

\begin{abstract}
To encourage private actions for damages in antitrust cases some jurisdictions subtract a fraction of the redress from the fine. We analyze the effectiveness of this policy. Such a rebate does not encourage settlement negotiations that would otherwise not occur. If, however, the parties settle without the rebate, the introduction of the reduction increases the settlement amount, yet at the price of reduced deterrence for those wrongdoers who are actually fined. Under a leniency program the rebate does not affect the leniency applicant: she doesn't pay a fine that can be reduced. The overall effect of a fine reduction on deterrence is, therefore, negative.
\end{abstract}

Keywords: antitrust, damages, deterrence, leniency.

JEL: D43, K21, K42, L40

*We thank David Gilo, Igor Letina, Giancarlo Spagnolo, and Niklaus Wallimann for helpful comments. The usual disclaimer applies. The views expressed in this paper are those of the authors and do not necessarily represent those of the Swiss Competition Commission. Authors' address: Departement Volkswirtschaftslehre, Universität Bern, Schanzeneckstrasse 1, Postfach 8573, CH-3001 Bern, Switzerland.

†Universität Bern, CEPR, and Swiss Competition Commission, winand.emons@ vwi.unibe.ch.

†Universität Bern, severin.lenhard@vwi.unibe.ch. 


\section{Introduction}

Antitrust rules are enforced publicly by competition agencies, typically by way of fines. Moreover, they can be enforced privately by the victims of an infringement through damage actions. In quite a few jurisdictions there is concern about the underdevelopment of private antitrust enforcement. For example, while in the US private cases already amount to at least $90 \%$ of antitrust enforcement, in the EU no more than $10 \%$ of antitrust enforcement was private. ${ }^{1}$ During the period 2006-2012 less than $25 \%$ of the Commission's infringement decisions were followed by private damages actions. Cases were mostly brought in Germany, the Netherlands, and the United Kingdom, while no follow-on actions were reported in 20 out of 28 member states. ${ }^{2}$

Several factors contribute to this underdevelopment: Typically, jurisdictions in Europe do not allow for collective actions and do not award punitive damages. Furthermore, the plaintiff in a civil suit does not have the means of an antitrust authority like dawn raids etc. to prove the infringement. ${ }^{3}$ Finally, the plaintiff assumes substantial expense risk, in particular if the English cost allocation rule applies and contingency fees are not allowed.

To encourage private antitrust enforcement the EU adopted Directive 2014/104/EU in 2014. The Directive establishes the right of victims to obtain full compensation for the harm caused by an anti competitive conduct. Full compensation includes actual losses and loss of profit, plus interest from the time the harm occurred until compensation is paid. In order to ensure that the right to full compensation is effectively guaranteed, the Directive introduces a number of measures which should facilitate antitrust damages claims in EU Member States. ${ }^{4}$

One measure that has been put forward lately is to subtract part of

\footnotetext{
${ }^{1} \mathrm{EU}(2006)$.

${ }^{2}$ OECD (2015).

${ }^{3}$ The burden of proof is, however, lower in a civil than in an administrative suit.

${ }^{4}$ For details about the measures, see, e.g., OECD (2015).
} 
the redress paid to the victims from the fine. For example, in its decisions Strassenbau and Engadin II (3.9.2019), the Swiss Competition Commission subtracted half of the settlement payment paid by the bid rigging construction companies to the victim (the Canton of Graubünden) from the wrongdoers' fines. ${ }^{5}$ Likewise, in June 2014 the Israeli Antitrust Tribunal approved a consent decree reached between Israeli banks who allegedly exchanged information and the Israeli Antitrust Authority providing that the entire settlement payment would be subtracted from the wrongdoers' fine. ${ }^{6}$

The EU also allows for this possibility. For instance, the Directive (EU) 2019/1 of the European Parliament and of the Council states: (47)... "NCAs (national competition authorities) should be able to take into account any compensation paid as a result of a consensual settlement" and in Article 14(2) "Member States shall ensure that national competition authorities may consider compensation paid as a result of a consensual settlement when determining the amount of the fine to be imposed for an infringement of Article 101 or 102 TFEU, in accordance with Article 18(3) of Directive 2014/104/EU." 7

In this paper we analyze whether rebating fines indeed stimulates private damage actions. Furthermore, we study the effects on deterrence, in

\footnotetext{
${ }^{5}$ www.newsd.admin.ch/newsd/message/attachments/58229.pdf

${ }^{6}$ See $\mathrm{H}^{\prime \prime} 43129-03-10$ Bank Hapoalim Ltd. v. Director General of the Israeli Antitrust Authority (15.6.2014).

${ }^{7}$ eur-lex.europa.eu/legal-content/EN/TXT/?uri=uriserv:OJ.L\&_.2019.011.01.0003.01. ENG\&toc=OJ:L:2019:011:TOC. In two cases, Pre-Insulated Pipes Cartel [1999] OJ L24/1 and Nintendo [2003] OJ L255/33, the European Commission granted reductions of fines in recognition of the fact that the wrongdoers had paid substantial compensation. The European Commission refused to grant reductions in other cases. The EC Court of First Instance confirmed in Archer Daniels Midland v Commission [2006] ECR II-3627 that there is no obligation to grant such reductions. The UK offers to reduce the fine by $5-10 \%$ should an undertaking make a voluntary redress in the processing on imposing penalty. In Korea the competition agencies can apply a 20-30\% reduction. In Turkey the fine can be reduced at a rate of $25-60 \%$. In Canada restitution is a factor that can be taken into account by a court in imposing a sentence for a criminal offence. The Dutch and Spanish competition authorities take into account voluntary compensation as a mitigating circumstance in setting the fine. In the US the Department of Justice does not grant rebates; there voluntary compensation is one of the conditions for obtaining leniency. See Wils (2009), OECD (2015), and Cartel Working Group (2019).
} 
particular if a leniency program applies.

A firm has been fined by the antitrust authority for anti competitive behavior. The victim seeks damages. The victim and the firm may settle the case out-of-court. The competition authority subtracts a fraction of the settlement payment from the wrongdoer's fine. If they do not reach a settlement, the victim can take the case to court.

The players' payoffs from going to court determine their threat points in the bargaining stage. They split the surplus created by settlement evenly. If the plaintiff does not go to court in the last stage, his outside option whilst bargaining is zero. The defendant will, therefore, not settle. This holds independently of the amount that is subtracted from the defendant's fine. Rebating the fine thus does not stimulate settlements that would otherwise not occur.

If the plaintiff goes to court, the parties settle without the rebate. Introducing the reduction increases the settlement amount: the rebate increases the surplus and at the same time lowers the defendant's marginal cost of settling. Thus, if parties settle without the rebate, its introduction increases the settlement amount.

Ex ante the prospect of paying the fine and the settlement potentially deter the defendant. The rebate lowers the fine and at the same time increases the settlement. In our set-up the first effect is stronger than the second onedeterrence, therefore, goes down.

Then we look at a leniency applicant under a leniency program. Since the leniency applicant is exempted from the fine, she does not care about the rebate. The rebate reduces deterrence for non whistle blowers. It does not affect deterrence for the leniency applicant. The relative incentive to turn the cartel members in, therefore, goes down. Consequently, the overall effect of a rebate on deterrence is negative.

Finally, we show that our results remain true if the agents have asymmetric rather than symmetric information. 
Rebating fines is thus not a clever idea in our framework. It does not stimulate settlements that would not occur absent the rebate. If parties settle without the reduction, the rebate increases the settlement amounthowever, at the price of reduced deterrence. Moreover, the rebate makes it less attractive for a cartel member to blow the whistle under a leniency program.

\section{$1.1 \quad$ Related Literature}

We are not aware of any formal papers focusing on fine rebates. There is a literature concerning private and public enforcement of antitrust laws. ${ }^{8}$ Shavell (1997) analyzes the divergence between the private and social motives to sue. When a plaintiff contemplates litigating, he does neither consider the legal costs incurred by others, nor does he recognize the positive effects on deterrence. Shavell discusses several corrective policies, one of which is to foster settlement over trial. McAfee et al. (2008) show that if courts are accurate, adding private to public enforcement increases welfare; if courts are not accurate, private enforcement increases welfare only if the government is inefficient in litigation. Bourjade et al. (2009) study antitrust litigation and settlement under asymmetric information. They find that increasing damages induce more private litigation of well-founded cases than reducing filing costs.

Buccirossi et al. (2019) analyze whether private actions for damages may jeopardize leniency programs. The evidence provided by the leniency applicant may be used in the damage action. Moreover, since the leniency applicant typically does not challenge the decision of the antitrust authority, under joint liability she may be the first one to be targeted in a private action. $^{9}$ Buccirossi et al. show that damage actions improve a leniency

\footnotetext{
${ }^{8}$ See, e.g., Segal and Whinston (2007) for a survey.

${ }^{9}$ There are, however, exceptions. In the air cargo cartel Lufthansa received full immunity from fines under the European Commission's leniency program because it was the first to provide information about the cartel (europa.eu/rapid/press-release_IP-10-
} 
program if civil liability of the immunity recipient is minimized and full access to all evidence gathered by the competition authority is given to the claimants.

There is a fairly large literature on settlement bargaining. It typically finds that with symmetric information parties settle rather than file a costly suit. To generate litigation the literature resorts to asymmetric information. The workhorses are either screening models where the uninformed party screens for private information using the settlement proposals (Bebchuck (1984) and Nalebuff (1987)), or signalling models where the informed party signals private information with the settlement offers (Reinganum and Wilde (1986)). ${ }^{10}$ We follow Nalebuff (1987).

The rest of this paper is organized as follows. The next section describes the model. In section 3 we derive our results on settlement and deterrence under symmetric information. In section 4 we analyze the asymmetric information setup. The last section concludes. In Appendix 1 we show that our symmetric information results also hold for any division of the settlement surplus as well as for the Nash Bargaining Solution. Appendix 2 contains the derivation of the asymmetric information scenario.

\section{Model}

A firm has engaged in anticompetitive behavior by, e.g., participating in a cartel. The competition authority has, therefore, levied the firm a fine $f>0$. The victim of the infringement contemplates obtaining damages from the wrongdoer in a civil suit. ${ }^{11}$

1487_en.htm?locale=en). Nevertheless, Lufthansa filed an appeal "based on legal considerations" (bloomberg.com/news/2011-01-27/japan-airlines-appeals-48-8-million-antitrustfine-at-eu-court.html).

${ }^{10}$ See, e.g., Kennan and Wilson (1993) or Spier (2007) for surveys.

${ }^{11}$ We model private enforcement as an action that follows on a public enforcement decision. Private enforcement can also be a stand-alone action - a civil action brought without any prior finding of competition law violation by an antitrust authority. In most jurisdictions private enforcement is, however, mostly represented by follow-on private actions; see 
If the victim decides to go for damages, the parties first try to reach an out-of-court settlement; the victim then gets $s \geq 0$ from the wrongdoer and drops the case. If settlement negotiations fail, the victim/plaintiff can take the firm/defendant to court. Going to court costs each party to the conflict $c>0$. The court awards (expected) damages $D>0$ to the plaintiff. Going to court thus generates payoffs $D-c$ for the plaintiff and $-f-D-c$ for the defendant. ${ }^{12}$

The payoffs from the court's decision determine the players' outside options/threat points in the settlement negotiations. We do not model the bargaining process explicitly. We rather assume that the settlement amount $s$ is determined such that the plaintiff gets half of the surplus generated by settlement.

The antitrust authority wants to stimulate settlement negotiations. It will subtract the fraction $\lambda \in[0,1]$ of the settlement payment from the fine. The wrongdoer will, therefore, end up with a net fine of $f-\lambda s$. Let $f \geq 2 D$. Then the net fine is always non-negative and we avoid tedious sub cases; we analyze small fines in Appendix 1. ${ }^{13}$

\section{Results}

We solve the game by backward induction. After negotiations have failed, the plaintiff takes the case to court if it has positive expected value, i.e., if $D-c>0$; otherwise, he drops the case, leading to a payoff of 0 for the plaintiff and $-f$ for the defendant.

Let us now turn to the settlement stage. If the plaintiff drops the case, by settling the parties do not save the cost of going to court; the surplus consists only of the subsidy $\lambda s$. The plaintiff's outside option in the bargaining pro-

OECD (2015).

${ }^{12}$ The firm made a profit and the victim suffered a loss from the anticompetitive behavior. Yet, these payoffs are sunk for the problem under consideration.

${ }^{13}$ In Appendix 1 we also deal with general divisions of the surplus. Furthermore, we derive the Nash Bargaining Solution. 
cess is 0 . Furthermore, he gets his share $.5 \lambda s$ of the surplus. Therefore, his payoff is $.5 \lambda s$ which he gets through the defendant's settlement payment $s$. Formally we have $.5 \lambda s=s$ which yields $s=0$. Viewed from the defendant's perspective: she pays $s$ to the plaintiff and gets only her share $.5 \lambda s$ of the surplus thus created.

Consider now the case where the plaintiff goes to court. By settling the parties save the cost $2 c$ and generate the subsidy $\lambda s$. The plaintiff's outside option is $D-c$. He gets his share $.5(2 c+\lambda s)$ of the surplus. Accordingly, his payoff is $D-c+.5(2 c+\lambda s)$ which he gets through the defendant's payment $s$. This means $D+.5 \lambda s=s$ which, in turn, yields $s=D /(1-.5 \lambda)$.

In the first stage, the plaintiff will go for damages if $s>0$ or, equivalently, $D-c>0$; otherwise, he will not try to collect damages.

To sum up: If $D-c>0$, the plaintiff goes for damages. The parties agree on the settlement payment $s=D /(1-.5 \lambda)$. Without settlement the plaintiff would take the case to court. The plaintiff ends up with payoff $s$ while the defendant gets $-f-(1-\lambda) s$. If $D-c \leq 0$, the plaintiff will not go for damages. He has payoff 0 and the defendant ends up with $-f$.

\subsection{Settlement Stimulation}

This result has several interesting implications. If $D-c<0$, the plaintiff will not litigate if asked to do so. In the negotiation stage, the threat to go to court is not credible. The solution concept of subgame perfection/backward induction implies that the defendant ignores empty threats and, therefore, does not settle. This result holds for any value of the rebate $\lambda$ : Even if the full amount of the settlement can be subtracted from the fine (like in the Israeli case mentioned in the Introduction), there will be no settlement unless the plaintiff indeed takes the case to court. To stimulate settlement negotiations that would otherwise not take place, subtracting the settlement payment from the fine is ineffective. To trigger settlement bargaining, the plaintiff has to be induced to actually take the case to court. This can, e.g., 
be achieved by increasing $D$ or lowering $c .^{14}$

Consider now the case $D>c$. Here the plaintiff would take the case to court and the parties, therefore, agree on the settlement $s=D /(1-.5 \lambda)$. The settlement amount is increasing in $\lambda$ at an increasing rate. ${ }^{15}$ Thus, if the competition authority wants larger settlement amounts, increasing the fraction $\lambda$ that can be subtracted from the fine is effective- given the parties engage in settlement negotiations in the first place.

The fraction $\lambda$ affects the settlement via two channels. First, reducing the fine increases the surplus of not going to court, thus making the pie larger. Second, the higher $\lambda$ the lower the defendant's marginal cost of settling: for each unit the plaintiff obtains, the defendant effectively only pays $(1-\lambda)$. For example, in the aforementioned Israeli case where $\lambda=1$, each Shekel the plaintiff got was entirely subtracted from the fine so that banks' marginal cost was zero. ${ }^{16}$

\subsection{Deterrence}

Let us now turn to deterrence. The defendant is deterred by the sum of the fine and damages. We denote this total payment which eventually deters by $z$.

If $D \leq c, s=0$ and $z=f$. Consider now the interesting case $D>c$. Increasing $\lambda$ increases the reduction in the fine, making the surplus from settlement larger. The surplus is shared equally, implying that not only the plaintiff but also the defendant benefits from a reduction in fine. Specifically, $z=f+(1-\lambda) D /(1-.5 \lambda)$. The total payment is decreasing in $\lambda .{ }^{17} \mathrm{In}$ -

\footnotetext{
${ }^{14}$ It seems difficult for the competition authority to influence $D$ and $c$ which are after all in the realm of the civil court. The antitrust agency could, e.g., grant access to documents from the antitrust case to the plaintiff, thus lowering $c$ and increasing $D$.

${ }^{15}$ Formally, $\partial s / \partial \lambda=2 D /(2-\lambda)^{2}>0$ and $\partial^{2} s / \partial \lambda^{2}=4 D /(2-\lambda)^{3}>0$.

${ }^{16}$ The two effects are reminiscent of the income and substitution effects in consumption resulting from a price decrease. The second effect is more pronounced in the Nash Bargaining Solution derived in the Appendix.

${ }^{17}$ Formally, $\partial z / \partial \lambda=-2 D /(2-\lambda)^{2}<0$ and $\partial^{2} z / \partial \lambda^{2}=-4 D /(2-\lambda)^{3}<0$.
} 
creasing $\lambda$ increases $s$ - the marginal effect on the settlement. However, the fraction the wrongdoer deducts goes up as well and also applies to the inframarginal settlement amount. The effect from reducing the inframarginal units is stronger than the marginal effect: the total payment of a cartel member is lower, the higher the reduction in fine $\lambda$. Consequently, deterrence is weakened if firms anticipate the reduction in fine.

Given that the fine reduction weakens deterrence for an "ordinary" cartel member, it is interesting to analyze the effects on a leniency applicant under a leniency program; we use the subscript $a$ for the applicant and no subscript for the other cartelists. ${ }^{18}$ Suppose the leniency program grants full leniency to the first applicant. Since the applicant's fine is zero, it cannot be reduced in case of a settlement.

Consider now the two cases: If $D \leq c$, the plaintiff does not go to court so that $s=0$; the applicant's total payment $z_{a}=0$. If $D>c$, the plaintiff's threat to sue the applicant is credible. The total surplus from an out-of-court settlement is $2 c$, there is no fine that can be reduced. The plaintiff has the outside option $D-c$ and gets half of the surplus $2 c$ through the settlement payment, i.e., $D-c+.5(2 c)=s$ which implies $z_{a}=D$.

The leniency applicant's total payment $z_{a}$ is thus either 0 or $D$. It is independent of $\lambda$. It is lower than her colleague's total payment $z$ which is either $f$ or $f+(1-\lambda) D /(1-.5 \lambda)$. Yet, for $D>c$ the colleague's total payment $z$ is decreasing in $\lambda$, so that the difference $z-z_{a}$ also shrinks. Consequently, the relative attractiveness of blowing the whistle (alternatively, the loss of being the sucker) goes down with $\lambda$. This argument actually holds for any level of liability of the leniency applicant. ${ }^{19}$ The fact that she pays no fine

\footnotetext{
${ }^{18}$ There is a fairly large literature on leniency programs; see, e.g., Motta and Polo (2003), Spagnolo (2004), or Chen and Rey (2013). For surveys see Harrington (2017) or Marvão and Spagnolo (2018).

${ }^{19}$ For example, in the EU Art. 11(4) of Directive 2014/104/EU provides "that an immunity recipient is jointly and severally liable as follows: (a) to its direct or indirect purchasers or providers; and (b) to other injured parties only where full compensation cannot be obtained from the other undertakings that were involved in the same infringe-
} 
that can be reduced drives the result. ${ }^{20}$

Whether the reduced deterrence is detrimental or not depends on the status quo. If we start out with underdeterrence, rebating the fine may increase underdeterrence. Suppose, by contrast, that the damage awarded by the court reflects the harm to the public. The total payment of damage plus fine exceeds the harm and potentially leads to overdeterrence. In this case, rebating the fine may reduce overdeterrence. ${ }^{21}$

\section{Asymmetric Information}

To illustrate the effects of a fine reduction under asymmetric information, we have to further specify the set-up, in particular the bargaining process. We choose the framework developed by Nalebuff (1987). ${ }^{22}$ The defendant has superior information about the damage than the plaintiff. ${ }^{23}$ Specifically, the defendant knows the realization $D$ of the damages. The plaintiff only knows that damages are drawn from a probability distribution. In Appendix 2 we consider the general case of log concave distributions; here we confine our attention to damages being uniformly distributed on $[0,1]$.

Bargaining proceeds as follows: In the first stage, the uninformed plaintiff makes a take it or leave it demand $s$. In the second stage, the informed defendant either accepts or rejects the settlement demand. If she accepts,

ment of competition law." In the US the 2004 Antitrust Criminal Penalty Enhancement and Reform Act eliminates treble damages and joint liability for the amnesty recipient.

${ }^{20}$ Note that we do not answer the general question of whether or not damage actions reduce the attractiveness of leniency programs. This issue is, e.g., addressed in Buccirossi et al. (2019).

${ }^{21}$ For these argument to be valid the firms must have several different possibilities to collude. With only one possibility, charging the monopoly price say, any sanction greater or equal to the harm deters monopoly pricing and there is no overdeterrence. To meaningfully talk about over- or underdeterrence, there must be more than one option to collude; see Emons (2020). For a discussion of sub-optimal cartel fines see, e.g., Bageri et al. (2013).

${ }^{22}$ Nalebuff (1987) extends Bebchuk (1984) to possible negative value claims.

${ }^{23}$ Osborne (1999) presents some empirical evidence that defendants actually do better in predicting court rulings than plaintiffs. 
bargaining is over. Otherwise, there is a third stage where the plaintiff either drops the case or proceeds to court.

If the case has ex ante a negative expected value, the defendant will reject any demand $s$. The plaintiff gets no new information through bargaining. He does not update his expectation and, therefore, does not litigate. This result corresponds to our symmetric information one and holds for any value of $\lambda$. Rebating the fine has thus no effect on deterrence.

Let us now turn to the other possibility where the case has ex ante positive expected value. Specifically, for our uniformly distributed damage example, assume the cost to go to court $c \leq 1 / 4$.

The equilibrium depends on the size of the fine. Let us sketch the outcome for a large fine $f \geq \lambda(1-c+2 \lambda c) /\left(1-\lambda^{2}\right)$. The plaintiff demands $s=$ $(1-c+2 \lambda c) /\left(1-\lambda^{2}\right)$. If the defendant accepts this demand, she incurs the cost $f+(1-\lambda) s$. If she rejects and the plaintiff takes the case to court, her cost is $f+D+c$. Defendants with $D \leq \hat{D}:=(1-2 c+\lambda c) /(1+\lambda)$, therefore, reject the demand; defendants with $D>\hat{D}$ accept. If the plaintiff takes the rejections to court, he expects to get $\hat{D} / 2$ which exceeds the litigation cost for $c \leq 1 / 4$. The plaintiff, therefore, indeed takes the rejected demands to court. $^{24}$ Note that the parties go to court for low $D$ even though this is inefficient - the typical outcome under asymmetric information; see Myerson and Satterthwaite (1983).

Let us now turn to deterrence. If $D \leq \hat{D}$, the defendant rejects, is taken to court, and ends up paying $f+D+c$. This total payment is independent of $\lambda$. If $D>\hat{D}$, the defendant accepts and the total payment is $z=f+(1-\lambda) s=$ $f+(1-c+2 \lambda c) /(1+\lambda)$. This total payment is decreasing in $\lambda .^{25}$ Increasing $\lambda$ increases $s$. Yet, the deductible fraction also goes up with the second effect stronger than the first one. Thus, reducing the fine decreases deterrence. ${ }^{26}$

\footnotetext{
${ }^{24}$ The results for medium and small fines are as follows: For all values of $f$ the plaintiff goes to court. If $f \in\left(\lambda(1-c), \lambda(1-c+2 \lambda c) /\left(1-\lambda^{2}\right)\right)$, the plaintiff demands $s=f / \lambda$ and $\hat{D}=f(1-\lambda) / \lambda-c$. For $f \leq \lambda(1-c), s=1-c$ and $\hat{D}=1-2 c-f$.

${ }^{25}$ Formally, $\partial z / \partial \lambda=(3 c-1) /(1+\lambda)^{2}<0$ for $c \leq 1 / 4$.

${ }^{26}$ The same result holds for medium values of $f$. For small values of $f$ increasing $\lambda$
} 


\section{Conclusions}

In this paper we have analyzed the effects of rebating fines by the redress paid to the victims. This policy turns out to be fairly ineffective, if not counterproductive, in our set-up. It does not stimulate settlements that would otherwise not take place. If parties settle without the reduction, the rebate indeed increases the settlement amount-however, at the cost of reduced deterrence. Moreover, the rebate makes it less attractive for a cartel member to blow the whistle under a leniency program.

A few remarks are in order. Our results rely heavily on backward induction arguments. If the plaintiff does not take the case to court, he has no credible threat in the settlement negotiations. The defendant, therefore, rejects any settlement demand in the first place, independently of the rebate. Backward induction/subgame perfection is probably the most widely accepted refinement of the Nash equilibrium concept. Any results which are based on empty threats would not seem convincing to us.

For our findings on deterrence the defendant needs to rationally foresee the fine reduction. This applies, e.g., if the rebate is a well established policy of the antitrust authority. This was probably not the case in the Swiss decisions. The Swiss Competition Commission granted the rebate for the first time in 2019. It seems unlikely that the construction companies anticipated the fine reduction when they engaged in bid rigging during the years 2004-2012. If the rebate is an unexpected or a random event like in the $\mathrm{EU}$, it has no or little effect on deterrence.

We have focused on follow-on private actions which is the prevailing form of private enforcement. The analysis of stand-alone private actions raises some additional issues: Are there at all follow-on public actions with a fine that can be reduced? Does the antitrust authority subtract only uncontested

has no effect on deterrence. Note that $\hat{D}$ decreases with $\lambda$ : the higher the rebate, the fewer cases are prosecuted. This has, however, no effect on deterrence because type $\hat{D}$ is indifferent between accepting $s$ and going to court. 
redress as in our set-up, or is contested redress also eligible? These questions are left for future research.

\section{Appendix 1}

In this Appendix we generalize the surplus splitting under symmetric information to any division $\alpha:(1-\alpha)$ where $\alpha \in(0,1)$ is the plaintiff's share. Furthermore, we properly take into account that $f-\lambda s \geq 0$. Finally, we also derive the Nash Bargaining Solution.

Let us first generalize the framework of the main text: rather than getting $50 \%$ of the surplus created through settlement, the plaintiff may get any share $\alpha \in(0,1)$.

If $D-c \leq 0$, the plaintiff will not take the case to court and $s=0$. If $D-c>0$, the plaintiff goes to court. His payoff is $D-c+\alpha(2 c+\lambda s)$ which he gets through the settlement payment $s$. Accordingly, the settlement is $(D-c+2 \alpha c) /(1-\alpha \lambda)=: \hat{s}$. If $\lambda \hat{s} \geq f$, the defendant cannot subtract the entire amount $\lambda \hat{s}$ from her fine but only $f / \lambda$. Settlement creates the surplus $2 c+f$ of which the plaintiff gets his share $\alpha$. We immediately obtain $D+c(2 \alpha-1)+\alpha f=: \check{s}$ which is independent of $\lambda$. Accordingly, for $D-c>0$,

$$
s= \begin{cases}\hat{s}, & \text { if } \lambda \hat{s} \leq f \\ \check{s}, & \text { otherwise }\end{cases}
$$

The unconstrained $\hat{s}$ is increasing in the plaintiff's share $\alpha$ as well as in $\lambda$. The qualitative results derived in the main text continue to hold.

Let us now turn to the Nash Bargaining Solution (NBS) which yields a different outcome than the bargaining process considered so far. ${ }^{27}$ In our framework $s$ is not only a transfer of surplus from the defendant to the plaintiff; it is also a means to increase the size of the surplus.

Let $\alpha \in(0,1)$ denote the bargaining power of the plaintiff and $(1-\alpha)$ the bargaining power of the defendant. The plaintiff settles if $s \geq \max \{0, D-c\}$. The defendant can at most reduce his fine to zero, i.e., she settles if $s+\max \{f-\lambda s, 0\} \leq$ $D+c+f$.

Consider first the case $D \leq c$. The NBS $s^{*}$ maximizes

$$
s^{\alpha}(-s-\max \{f-\lambda s, 0\}+f)^{1-\alpha} .
$$

\footnotetext{
${ }^{27}$ For more on the NBS see, e.g., Roth (1979). Binmore, Rubinstein, and Wolinsky (1986) analyze the relation between the static NBS and a sequential bargaining model à la Rubinstein (1982).
} 
We have $s^{*}=0$ which is the same outcome as in the main text. With a non-credible threat of the plaintiff, there is no settlement payment.

Next suppose $D>c$; the plaintiff's threat to sue is thus credible. If the parties settle, the plaintiff gets $s$ and the defendant pays $s+\max \{f-\lambda s, 0\}$. The outside option if bargaining fails are $D-c$ for the plaintiff and $-D-c-f$ for the defendant. The NBS $s^{*}$ maximizes

$$
(s-D+c)^{\alpha}(-s-\max \{f-\lambda s, 0\}+f+D+c)^{1-\alpha}
$$

which yields the solution

$$
s^{*}= \begin{cases}\bar{s}, & \text { if } f \geq \lambda \bar{s} \\ f / \lambda, & \text { if } \lambda \hat{s} \leq f<\lambda \bar{s} \\ \check{s}, & \text { if } f<\lambda \hat{s}\end{cases}
$$

where $\bar{s}:=(1-\alpha)(D-c)+\alpha(D+c) /(1-\lambda), \hat{s}=(D-c(1-2 \alpha)) /(1-\lambda \alpha)$, and $\check{s}=D+c(2 \alpha-1)+\alpha f$.

If $s^{*}=\bar{s}$, we have qualitatively the same results as in the main text. The settlement is increasing at an increasing rate in $\lambda .^{28}$ The plaintiff's bargaining power as measured by $\alpha$ determines the distribution of the surplus. The gains for the plaintiff are $\bar{s}-(D-c)=\alpha(2 c+\lambda(D-c)) /(1-\lambda)$, and the gains for the defendant are $(1-\alpha)(2 c+\lambda(D-c))$. The plaintiff's gains more from the fine reduction than the defendant if $\lambda \geq(1-2 \alpha) /(1-\alpha)$. For $\alpha$ small, a large $\lambda$ is necessary for the plaintiff to gain more than the defendant; for $\alpha \geq 1 / 2$ the plaintiff does better for any $\lambda$.

Finally, let us compare $\bar{s}$ with $s=D /(1-.5 \lambda)$, the settlement with equal sharing of the surplus. The two approaches yield the same outcome for $\alpha=$ $(1-\lambda) /(2-\lambda)$. Thus, the higher $\lambda$, the less bargaining power $\alpha$ the plaintiff needs to obtain equal sharing of the surplus. The higher the reduction in fine, the less the defendant cares about the settlement amount so that the plaintiff needs less bargaining power to appropriate half of the pie.

\section{Appendix 2}

In this Appendix we derive the equilibrium under asymmetric information sketched in the paper for log concave distributions. The defendant knows the realization of $D$ while the plaintiff only knows its distribution. $D$ is distributed on $[\underline{D}, \bar{D}]$ with density $g$ and cdf $G$. The density has full support, is differentiable, and log

\footnotetext{
${ }^{28} \bar{s}$ is a supermodular function in $\alpha$ and $\lambda$, thus the effect on $\bar{s}$ from increasing $\lambda$ is stronger the higher $\alpha$.
} 
concave. Moreover, $\underline{D}<c$, i.e., negative value cases are possible. Let $D$ define the defendant's type.

In the first stage of bargaining the uninformed plaintiff makes a take it or leave it demand $s$. In the second stage the informed defendant either rejects or accepts the settlement demand. If she accepts, bargaining is over. If she rejects, there is a third stage where the plaintiff either drops the case or proceeds to court. Denote the probability that the plaintiff litigates by $\eta$.

If the parties settle out of court, the plaintiff gets $s$ and the defendant pays $z:=s+\max \{f-\lambda s, 0\}$. If the plaintiff litigates, he gets $D-c$ and the defendant pays $D+c+f$. The plaintiff gets zero and the defendant pays $f$ when the case is dropped.

For all possible values of $s$ we will first derive Nash equilibria for the subgames starting in stage 2 . Then we will determine the plaintiff's optimal demand $s$.

Consider first the defendant in stage 2. A defendant of type $D \geq D(s, \eta)$ accepts the settlement offer $s$, where

$$
D(s, \eta):=\frac{z(s)-\eta c-f}{\eta} .
$$

Next consider the plaintiff in stage 3. Since negative expected value claims are possible, there exists a unique cut-off value $\hat{D}$ where the plaintiff is indifferent between litigating or dropping the case. $\hat{D}$ is defined by

$$
\frac{1}{G(\hat{D})} \int_{\underline{D}}^{\hat{D}} x g(x) d x=\mathbb{E}[D \mid D \leq \hat{D}]=c .
$$

If $D<\hat{D}$, the plaintiff drops the case, thus $\eta=0$. If $D>\hat{D}$, the plaintiff litigates, i.e., $\eta=1$. If $D=\hat{D}$, the plaintiff is indifferent, accordingly, $\eta \in[0,1]$. The cut-off $\hat{D}$ is independent of $s$ and $\lambda$.

We distinguish between the two possibilities: the case has a priori negative or positive expected value. Let us start with the easy one where $\mathbb{E}[D] \leq c$, i.e., the case has negative expected value. For all possible $s$ the defendant rejects the demand. The plaintiff learns nothing from the defendant's decision, sticks to his prior, and chooses $\eta=0$ since $\mathbb{E}[D] \leq c$. This result holds for any value of the rebate $\lambda$. For negative expected value cases subtracting the settlement payment from the fine is, therefore, ineffective in stimulating settlement negotiations.

Let us now turn to the interesting possibility where $\mathbb{E}[D]>c$, i.e., the case has a priori positive expected value. Suppose $\eta=1$. Then defendants with $D \leq D(s, 1)$ reject the demand. If $\hat{D} \leq D(s, 1)$, or equivalently $\mathbb{E}[D \mid D \leq D(s, 1)]>c$, the plaintiff will indeed go to court. If $\hat{D}>D(s, 1)$, or equivalently $\mathbb{E}[D \mid D \leq D(s, 1)]<$ $c$, the plaintiff will not go to court: a pure strategy equilibrium fails to exist. 
Therefore, we construct a mixed strategy equilibrium. The plaintiff is willing to mix in stage 3 if $D(s, \eta)=\hat{D}$ which immediately yields $\eta=(z-f) /(\hat{D}+c)$. Defendants with $D<\hat{D}$ reject $s$. Plaintiffs are indifferent whether to drop the case or not.

We summarize these results in the following Lemma.

Lemma 1: Let $\mathbb{E}[D]>c$.

(i) If $\hat{D} \leq D(s, 1)$, the plaintiff litigates with $\eta=1$ and defendants of type $D>D(s, 1)$ accept while the others reject;

(ii) if $\hat{D}>D(s, 1)$, the plaintiff litigates with $\eta=(z-f) /(\hat{D}+c)$ and defendants of type $D>D$ accept while the others reject.

Lemma 1 establishes for any settlement demand $s$ an equilibrium for the ensuing subgame. The plaintiff thus chooses $s$ so as to maximize

$$
(1-G(D(s))) s+G(D(s)) \eta(s)(\mathbb{E}[D \mid D \leq D(s)]-c) .
$$

With probability $(1-G(D(s)))$ the defendant accepts and pays $s$. With probability $G(D(s))$ ) the defendant rejects the demand. The plaintiff litigates with probability $\eta(s)$ which yields in expectation $\mathbb{E}[D \mid D \leq D(s)]$ at a cost $c$. With probability $(1-\eta(s))$ he drops the case and gets nothing.

Rather than solving the plaintiff's problem directly for $s$, we determine the defendant's total payment $z$ where $s=\min \{(z-f) /(1-\lambda), z\}$. The plaintiff thus picks $z$ so as to maximize

$$
V(z)=(1-G(q(z))) \min \left\{\frac{z-f}{1-\lambda}, z\right\}+G(q(z)) \beta(z)(\mathbb{E}[D \mid D \leq q(z)]-c),
$$

where $\beta(z):=\min \{(z-f) /(\hat{D}+c), 1\}$ and $q(z):=(z-\beta(z) c-f) / \beta(z) . V(z)$ is continuous; furthermore, it is differentiable except at $z=f / \lambda$ and $z=\hat{D}+c+f$.

$V(z)$ is strictly increasing if $z \leq \hat{D}+c+f$ : The condition implies the case (ii) of Lemma 1, i.e., defendants of type $D \geq \hat{D}$ accept the plaintiff's demand. The threshold type is independent of $z$. Therefore, $G(q(z))$ does not dependent on $z$ while all remaining terms increase in $z$. Thus, the minimal payment of the defendant to the plaintiff is $\hat{D}+c+f$, which is independent of $\lambda$.

The equilibrium payment $z$ is given by the following proposition:

Proposition 1: If $\lambda \leq f /(\hat{D}+c+f)$, the defendant pays: 


$$
z= \begin{cases}\hat{D}+c+f, & \text { if } V_{1}^{\prime}(\hat{D}+c+f)<0 \\ z_{1}, & \text { if } V_{1}^{\prime}(\hat{D}+c+f) \geq 0>V_{1}^{\prime}(f / \lambda) \\ f / \lambda, & \text { if } V_{1}^{\prime}(f / \lambda) \geq 0>V_{2}^{\prime}(f / \lambda) \\ z_{2}, & \text { if } V_{2}^{\prime}(f / \lambda) \geq 0\end{cases}
$$

where $V_{1}^{\prime}(\cdot), V_{2}^{\prime}(\cdot), z_{1}$, and $z_{2}$ are defined in the proof. $z$ weakly decreases in $\lambda$.

If $\lambda>f /(\hat{D}+c+f)$, the defendant pays:

$$
z= \begin{cases}\hat{D}+c+f, & \text { if } V_{2}^{\prime}(\hat{D}+c+f)<0 \\ z_{2}, & \text { if } V_{2}^{\prime}(\hat{D}+c+f) \geq 0\end{cases}
$$

where $V_{2}^{\prime}(\cdot)$ and $z_{2}$ are defined in the proof. $z$ is independent of $\lambda$.

Proof: Consider first the case $\lambda \leq f /(\hat{D}+c+f)$. We split the plaintiff's problem into two parts:

$$
\begin{aligned}
& \max _{z} V_{1}(z)=(1-G(q(z))) \frac{z-f}{1-\lambda}+G(q(z))(\mathbb{E}[D \mid D \leq q(z)]-c) \\
& \text { s.t. } \hat{D}+c+f \leq z \leq f / \lambda,
\end{aligned}
$$

and

$$
\begin{aligned}
& \max _{z} V_{2}(z)=(1-G(q(z))) z+G(q(z))(\mathbb{E}[D \mid D \leq q(z)]-c) \\
& \text { s.t. } z \geq f / \lambda,
\end{aligned}
$$

with $q(z)=z-c-f$.

We first analyze problem (1) without constraints. The first order condition can be written as

$$
(1-\lambda) V_{1}^{\prime}(z)=1-G(q(z))-g(q(z))(2 c(1-\lambda)+(z-f) \lambda)=0 .
$$

Plugging the first order condition into the second order condition

$$
(1-\lambda) V_{1}^{\prime \prime}(z)=-g(q(z))(1+\lambda)-g^{\prime}(q(z))(2 c(1-\lambda)+(z-f) \lambda)<0
$$

and rearranging shows that the second order condition holds if

$$
g^{2}(\cdot)(1+\lambda)+g^{\prime}(\cdot)(1-G(\cdot))>0,
$$

which is true for $g(\cdot) \log$ concave. Consequently, if it is interior, there exists a unique maximum $z_{1}$. 
With the implicit function theorem we derive the sign of $d z_{1} / d \lambda$. Since $V_{1}^{\prime \prime}(z)<$ 0 , the sign is determined by the sign of

$$
\frac{\partial^{2} V_{1}(z ; \lambda)}{\partial z \partial \lambda}(1-\lambda)^{2}=1-G(q(z))-g(q(z))(z-f) .
$$

Plugging in the first order condition shows that this expression is negative if and only if $g(q(z))(1-\lambda)(-z+f+2 c) \leq 0$; this holds since $z \geq \hat{D}+c+f \geq 2 c+f$. We have thus shown that if the solution is interior, $z_{1}$ is decreasing in $\lambda$, which implies that deterrence is decreasing in the reduction of fine. ${ }^{29}$ Note that $q\left(z_{1}\right)$ is also decreasing, which implies that more defendants will accept the settlement demand: fewer cases will be taken to court.

Next consider problem (2). Ignoring the constraints, the first order condition can be written as

$$
V_{2}^{\prime}(z)=1-G(q(z))-g(q(z))(2 c+f)=0 .
$$

The second order condition is

$$
V_{2}^{\prime \prime}(z)=-g(q(z))-g^{\prime}(q(z))(2 c+f)<0
$$

and plugging in the first order condition and manipulating shows that the condition is equivalent to

$$
g^{2}(\cdot)+g^{\prime}(\cdot)(1-G(\cdot))>0,
$$

which holds for $g(\cdot) \log$ concave. Thus, there exists a unique maximum $z_{2}$ which is independent of $\lambda$. To have an interior solution, $V_{2}^{\prime}(f / \lambda)>0$.

Finally, consider the case $\lambda>f /(\hat{D}+c+f)$. The plaintiff's problem simplifies to

$$
\begin{aligned}
& \max _{z} V_{2}(z)=(1-G(q(z))) z+G(q(z))(\mathbb{E}[D \mid D \leq q(z)]-c) \\
& \text { s.t. } z \geq \hat{D}+c+f .
\end{aligned}
$$

Problem (3) has the same first order condition for an interior solution as problem (2). The solution does not depend on $\lambda$. The maximum is either $z=\hat{D}+c+f$ or, if $V_{2}^{\prime}(\hat{D}+c+f)>0$, the interior solution $z_{2}$. Thus, whenever $\lambda>f /(\hat{D}+c+f)$, there is no effect on the deterrence.

$z_{1}$ is decreasing in, while $z_{2}$ is independent of $\lambda$. Thus, when $z$ equals $z_{1}$ or $f / \lambda$, deterrence is decreasing in the rebate. All other payments of the defendant do not depend on $\lambda$. Consequently, deterrence is weakly decreasing in the fine reduction.

${ }^{29}$ The solution is interior if the following two conditions hold: $V_{1}^{\prime}(\hat{D}+c+f)>0$ and $V_{1}^{\prime}(f / \lambda)<0$. 


\section{References}

Bageri, V., Katsoulacos, Y., And G. Spagnolo, 2013. The Distortive Effects of Antitrust Fines Based on Revenue, Economic Journal 123, 545-557.

BeBchuck, L., 1984. Litigation and Settlement Under Imperfect Information, Rand Journal of Economics 15, 404-415.

Binmore, K., Rubinstein, A., And A. Wolinsky, 1986. The Nash Bargaining Solution in Economic Modelling, Rand Journal of Economics 17, 176-188.

Buccirossi, P., Marvão, C., And G. Spagnolo, 2019. Leniency and Damages: Where is the Conflict?, papers.ssrn.com/sol3/papers.cfm?abstract_id=2566774.

Bourjade, S., Rey, P., and P. Seabright, 2009. Private Antitrust Enforcement in the Presence of pre-trial Bargaining, Journal of Industrial Economics 57, 372-409.

Cartel Working Group, 2019. Development of Private Enforcement of Competition Law in ICN Jurisdictions, ec.europa.eu/competition/cartels/icn/private_enforcement_chapter_en.pdf.

Chen, Z. And P. Rey, 2013. On the Design of Leniency Programs, Journal of Law and Economics 56, 917-957.

Emons, W., 2020. The Effectiveness of Leniency Programs when Firms choose the Degree of Collusion, International Journal of Industrial Organization 70, Article 102619.

EU, 2006. Making Antitrust Damages Actions more Effective in the EU: Welfare Impact and Potential Scenarios, Report for the European Commission Contract DG COMP/2006/A3/01228, ec.europa.eu/competition/antitrust/actionsdamages/ files_ white_paper/impact_study.pdf.

Harrington, J., 2017. The Theory of Collusion and Competition Policy, MIT Press, Cambridge, Massachusetts.

Kennan J. And R. Wilson, 1993. Bargaining with Private Information, Journal of Economic Literature 31, 45-104.

Marvão, C. and G. Spagnolo, 2018. Cartels and Leniency: Taking Stock of What We Learnt, in Handbook of Game Theory and Industrial Organization, 
Volume II, L. Corchón and M. Marini (eds.), Edward Elgar, Cheltenham.

McAfee, R., Mialon, H., And S. Mialon, 2008. Private v. Public Antitrust Enforcement: A Strategic Analysis, Journal of Public Economics 92, 1863-1875.

Motta, M. And M. Polo, 2003. Leniency Programs and Cartel Prosecution, International Journal of Industrial Organization 21, 347-379.

Myerson, R. And M. Satterthwaite 1983. Efficient Mechanisms for Bilateral Trading, 29 Journal of Economic Theory 29, 265-281.

Nalebuff B., 1987. Credible Pretrial Negotiation, Rand Journal of Economics 18, 198-210.

OECD, 2015. Relationship between Public and Private Antitrust Enforcement, www.concurrences.com/IMG/pdf/daf-compwp3_ 2015_14.pdf?40555/

8f29d71e1c5258415acc3f16be97a95141aec3ee.

Osborne E., 1999. Who Should Be Worried About Asymmetric Information in Litigation?, International Review of Law and Economics 19, 399-409.

Reinganum, J. And L. Wilde, 1986. Settlement, Litigation, and the Allocation of Litigation Costs, Rand Journal of Economics 17, 557-566.

Roth, A., 1979. Axiomatic Models of Bargaining, Springer, Berlin.

Rubinstein A., 1982. Perfect Equilibrium in a Bargaining Model, Econometrica 50, 97-109.

Segal, I. And M. Whinston, 2007. Public vs Private Enforcement of Antitrust Law: A Survey, European Competition Law Review 28, 306-315.

Shavell, S., 1997. The Fundamental Divergence between the Private and the Social Motive to Use the Legal System, Journal of Legal Studies 24, 575-612.

Spagnolo, G., 2004. Divide et Impera: Optimal Leniency Programmes, CEPR Discussion Paper No. 4840,

cepr.org/active/publications/discussion_papers/dp.php?dpno $=4840 \#$.

SpIER, K., 2007. Litigation, in Handbook of Law and Economics, M. Polinsky and S. Shavell (eds.), Elsevier, Amsterdam.

Wils W., 2009. The Relationship between Public Antitrust Enforcement and Private Actions for Damages, World Competition 32, 3-26. 